\title{
Some Hints to Develop Particular Line Pipe Specification
}

\author{
Ardian Fandika ${ }^{1, *}$ \\ ${ }^{1}$ PERTAMINA HULU MAHAKAM, RPE Division, Balikpapan, Indonesia
}

\begin{abstract}
When procuring the carbon steel line pipe for pipeline project, frequently the purchaser refers to the international standards/specifications such as API SPEC 5L without any particular requirements. Many users thought these standards/specifications already addressed what are needed in their project; but unfortunately it is not completely true. The specification such as API SPEC 5L clearly mentioned in the special notes section that the users should not rely exclusively on the information contained in the specification and it is users' responsibilities to define the product characteristics which meet the design criteria and suitable for the construction and the operation of the installation (e.g. pipeline). Through this paper, the author tries to give some ideas on particular specification for line pipe.
\end{abstract}

\section{Introduction}

Within the pipeline project, it is a common approach that the owner, purchaser, contractor or the operator used international specification such as API SPEC 5L [1] as technical reference document. The API itself has mentioned in the special notes that the users should not rely exclusively on the information contained in the specification and API emphasized sound business, scientific, engineering, and safety judgment should be used in the employing the information contained in the specification.

API SPEC 5L provide line pipe technical specification for wide range of pipeline applications such as for liquid or gas transmission, sweet and sour service, onshore and offshore pipeline, etc. It is users' responsibilities to define the product characteristics which meet the design criteria and suitable for the construction and the operation of the installation.

In author's opinion, in order to have uniform product characteristics, it is necessary to give the proper tolerance on each essential parameter. And based on the impact of process parameters and the specific applications, the essential parameters and its tolerances may be adjusted.

\section{Quality approach}

In order to ensure the quality, the pipe shall be tested; however, for many reasons, it is impossible to test each of pipes and therefore sampling is needed. The sample is considered as representative of a production lot only if the sample covers the variety of the products. Logically, the less variation in the product then the bigger lot quantity and the smaller sample quantity can be. Statistically, API requires sampling maximum $1 \%$ (i.e. one test per test unit of not more than 100 pipes).
One important aspect to have high confident level on quality based on the statistical approach is by having the product with limited process variation (i.e. the process is as uniform as possible). For this reason, it is necessary to have the understanding which aspect that should be controlled to limit variations in final product characteristics.

Homogeneity concept is introduced based on the influences of process parameters (so called essential process parameters) to the desired product final properties. How homogeneity shall be maintained depends on the specific property intended for the service.

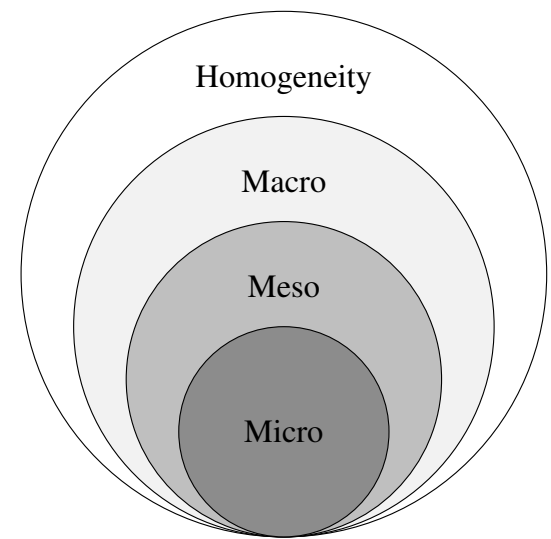

Fig. 1. Homogeneity concept.

For example, essential process parameters for line pipe designated for sour service will certainly be difference with the line pipe for sour service. In sweet service application, the hardness between $240 \mathrm{HV}$ and $260 \mathrm{HV}$ makes no difference in pipeline operation; but not in sour service application (e.g. sour service region 3 according to ISO 15156-2 [2]).

It is difficult to ensure the hardness level uniformity on the material unless the process can be controlled in such a way that process variations will not cause 
hardness variation exceeding the acceptable range. And furthermore, it's necessary to know which process parameters to be controlled.

The relationship between process, microstructure, and steel properties is complex. There are so many combinations and it's difficult to quantify the influence of more than one parameter into the final product properties.

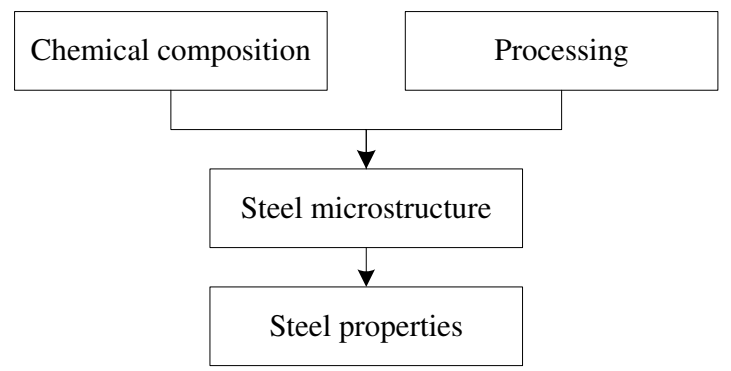

Fig. 2. Steel microstructure - properties relationship.

Within the homogeneity concept, the target is to limit the variation of a single parameter and by doing so; the variation on final product can be restricted as well. By knowing the influence of each process parameters, it is possible to limit re-qualification test in case of the deviation occurs.

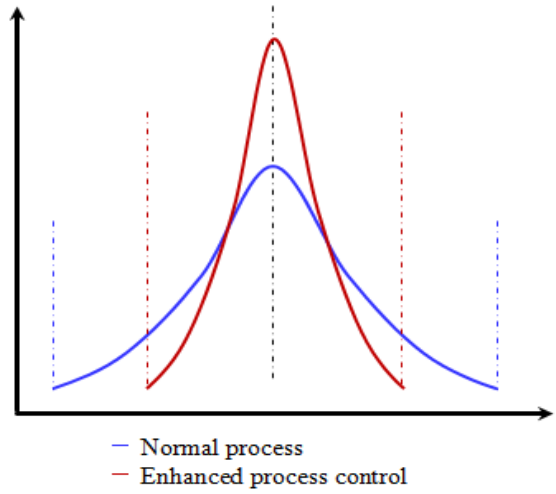

Fig. 3. Illustration of enhanced process control to limit process variations.

\section{Chemical compositions}

At a given manufacturing process, chemical composition affect the mechanical properties of the pipe. It has been discussed in many books and papers on how and in which way chemical composition can affect the mechanical and weldability properties of the pipe.

Figure 4 [3] and Figure 5 [4] are the examples of influence of alloying element to the yield stress and ductile-to-brittle transition temperature. Figure 6 [5] show the influence of microalloying additions to the austenite grain coarsening during the reheating process of slab or billet.

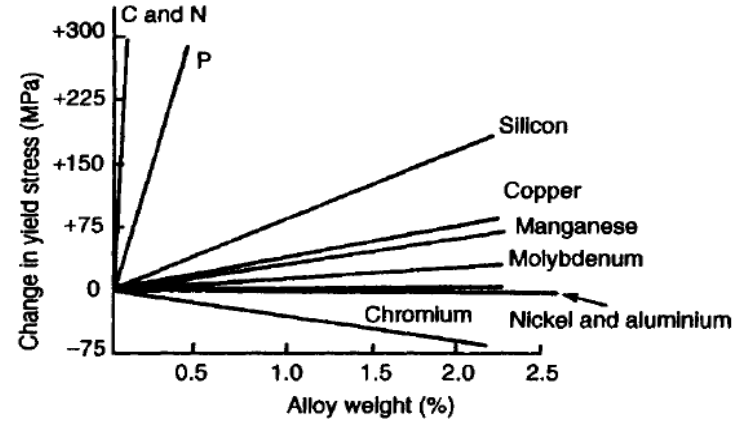

Fig. 4. Solid solution strengthening effects in ferrite-pearlite high-strength low-alloy steels.

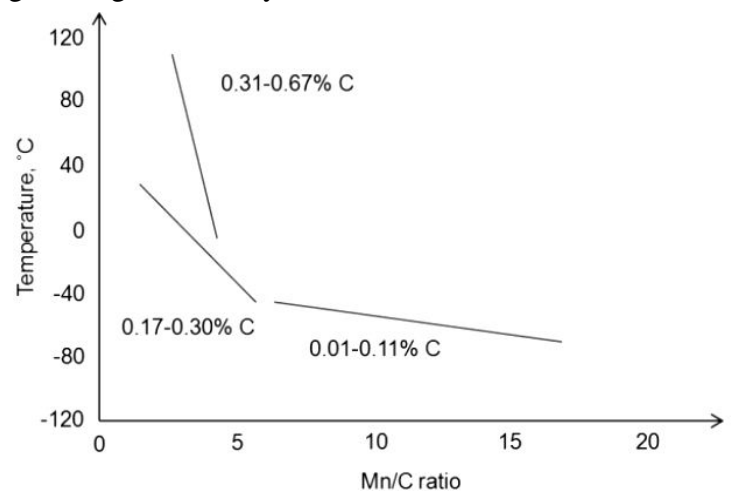

Fig. 5. Effect of manganese/carbon ratio on the transition temperature of ferritic steels.

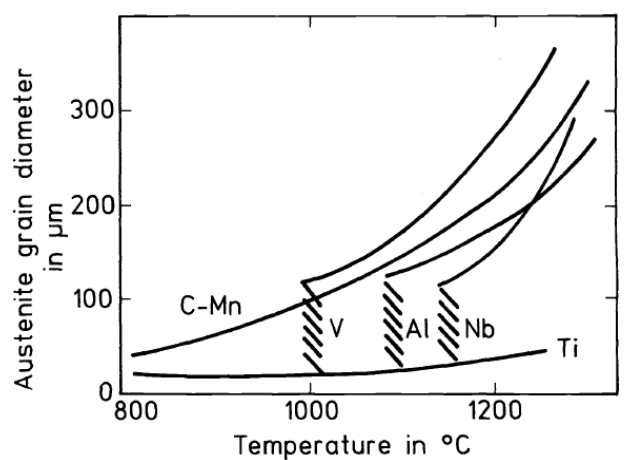

Fig. 6. Austenite grain coarsening characteristics for steel containing various microalloying additions.

On the chemical composition, it's a good approach to give some reasonable tolerance, but this needs to be discussed with the mill on how consistent they can maintain chemical composition on the steel. It could be further agreed between the mill and the purchaser that the qualification tests to be done at maximum and minimum alloying content to validate the tolerance.

DNVGL-ST-F101 does specify the change in ladle analysis for C-Mn steels outside $\pm 0.02 \% \mathrm{C}, \pm 0.03 \mathrm{CE}$ and/or \pm 0.02 in $\mathrm{Pcm}$ will requires new qualification test.

These limitations are considered sufficient for most of pipeline application; however for specific one (e.g. severe sour service), the user should look more detail into the particular alloying element and in combination with process parameters in order to get the suitable properties.

Steel mills should have the internal requirements and procedures to control the chemical variation during the steelmaking process; but normally this practice is not being communicated to the purchaser and considered as confidential information. 


\section{Rolling process}

There are four delivery conditions specified in API SPEC 5L; as-rolled (AR), normalizing/normalizing rolled $(\mathrm{N})$, quenching and tempering $(\mathrm{Q})$, and thermomechanical rolled (M). Nowadays, most of high grade welded pipes are manufactured with delivery condition $\mathrm{M}$ (thermomechanical rolled), while seamless pipe with delivery condition Q (quenched and tempered).

Unlike the others, thermomechanical process combines thermal and mechanical effect during manufacturing in order to achieve various and improved properties. For this reason, thermomechanical rolling process is more sensitive to the variation on process parameters than the others.

Based on recrystallization phenomena, thermomechanical rolling process can be split into recrystallization controlled rolling (RCR) and nonrecrystallization controlled rolling (N-RCR). Some rolling mills also apply rolling at lower temperature (e.g. dual-phase rolling) to produce steel with specific properties. Rolling at different temperature particularly beyond the limit of recrystallization or transformation may result in the different grain size.

After the rolling, the plate or coil will be cooled to room temperature with accelerated cooling device or cooling in still air; and the coil will be coiled while it is still hot.

Change in grain size and cooling rate will change the final microstructure and thus the steel properties. The schematic diagram of this process is shown in Figure 7 [6] below.

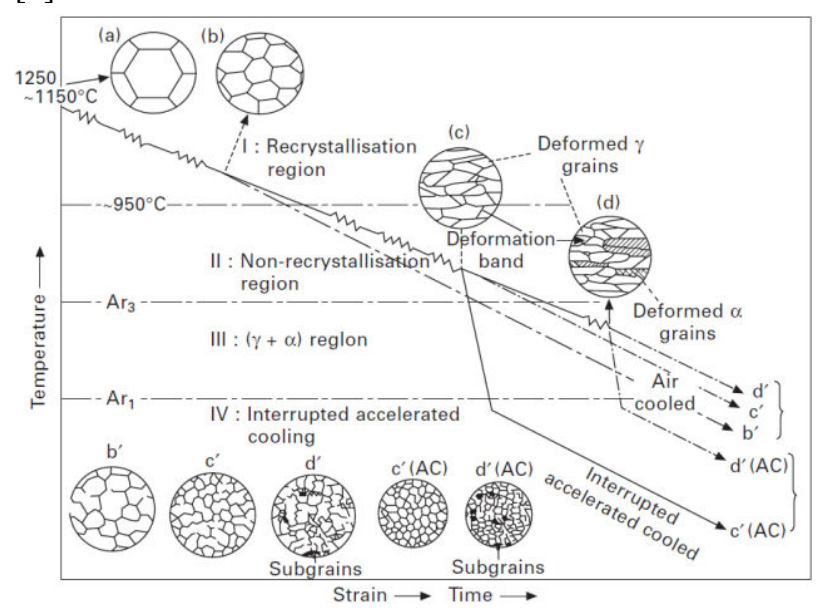

Fig. 7. Schematic diagram comparing the changes in relative austenite grain size and shape on the final ferrite grain size after different types of controlled processing.

For sour service application, normally the mill should avoid rolling process at temperature below $\mathrm{Ar}_{3}$ as it will create more heterogeneous microstructure (i.e. deformed austenite and ferrite at the same time).

API addresses the importance of defining the permissible ranges of critical variables for coil/plate rolling practice; however there is no specific value given in the document. Requirements for permissible ranges are available DNVGL-OS-F101 but limited to the slab reheating temperature, final rolling temperature, start and stop of accelerated cooling. Schematic comparison of thermomechanical control and conventional process is given in Figure 8 [7-8].

For seamless pipe, tolerance on temperature may not be as strict as for welded pipe. This is mainly due to the hardening process is obtained through heat treatment process (i.e. normalizing or quenching and tempering); however, it still important to control the temperature within the certain limit in order to limit the variability of pipe properties.

\section{Forming process}

Cold forming process for welded pipe making will cause strain hardening and change the mechanical properties of the steel, therefore it is necessary to perform straining analysis to measure the maximum value during forming. The mechanical tests then can be performed with the samples taken from the maximum strained area. Variation within the tolerance as specified in API SPEC $5 \mathrm{~L}$ is considered sufficient.

For non-integrated pipe mill, the pipe mill should consider their manufacturing process which can alter the plate/coil properties (e.g. bauschinger effect due to stress-strain process). This alteration shall be incorporated into manufacturing product specification when procuring the plates or coils. Performing mechanical tests on samples which is previously strained to simulate the forming process, is a good approach to quantify the effect of forming.

\section{Non-destructive testing (NDT)}

The standards referred by API SPEC 5L about the NDT method and technique give a lot of information, but still it is necessary to develop a specific procedure for each NDT process. This is to ensure the quality of the process as well as to give confident that the NDT system setup can achieve the required sensitivity level.

The procedure should specify the essential variables of each process and limits of application. In conventional automatic ultrasonic testing (AUT) of longitudinal weld seam, one example is about the thickness where frequently being forgotten by many who consider one system setup (e.g. number of probes, probe configuration, number of channel, etc) can be applied for all thickness.

In recent sour service pipeline failure with large diameter welded thermomechanical rolled pipes, the hard spot is recognized as root cause. The crack initiated on the hard spot located at pipe surface and propagates into the bulk material. The hard spots (i.e. the area with hardness level $>250 \mathrm{HV}$ ) are found scattered on the pipe surface. Referring to author's experience in sour service pipeline, it is necessary to apply NDT on the pipe surface to check the level of hardness and for practicality reason, this NDT process should be performed on plates rather than on finished pipe. 


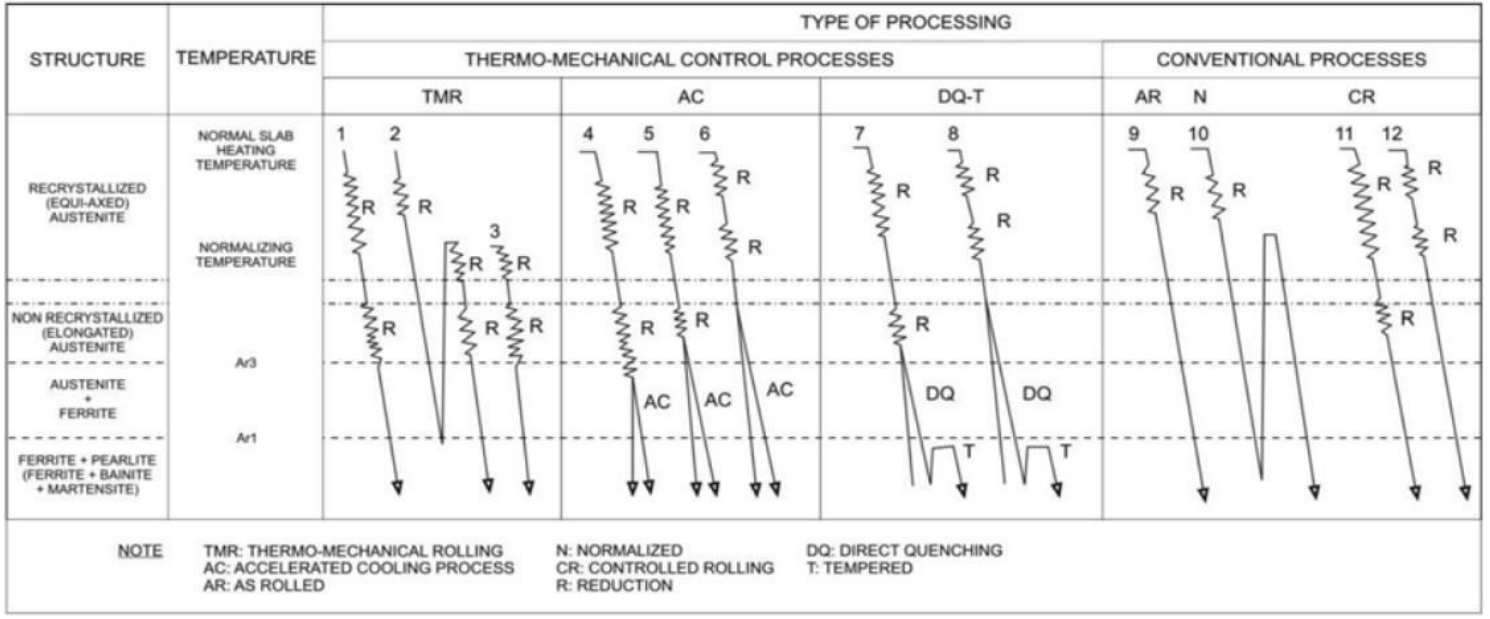

Fig. 8. Schematic diagram of thermomechanical control and conventional process for steel plate.

\section{Conclusions}

As international recognized specification, API SPEC 5L give a lot of information which are sufficient for most basic pipeline application and therefore should be considered as minimum requirements. API remind that the users shall take into account any particularity of each pipeline application and make sure the line pipe to be produced will suit the pipeline design, safe and can be operated as expected.

The quality control based on statistics of testing does not provide a robust system unless the population have limited variation that can ensure the uniformity of the final product.

Each pipe manufacturing process has different type of essential process parameters and it is important to control these parameters and ensure the mill has appropriate system to manage that. These parameters and acceptable range should be specified in the manufacturing procedure and subject to agreement between the purchaser and the manufacturer.

\section{References}

1. API Specification 5L, Specification for Line Pipe, $45^{\text {th }}$ Ed., Errata 1, (2015)

2. ISO 15156-2, Petroleum and natural gas industries - Materials for use in H2S-containing environments in oil and gas production - Part 2 - Crackingresistant carbon and low-alloy steels, and the use of cast irons, $3^{\text {rd }} \mathrm{Ed},(2015)$

3. D.T. Llewellyn, R.C. Hudd, Steels: Metallurgy and Application, $3^{\text {rd }}$ ed., (1998)

4. J.R. Davis, Alloying: Understanding the Basics, (2001)

5. Kozasu, I., Processing - Thermomechanical Controlled Processing. In Materials Science and Technology Vol.7, (1992)

6. E. Pereloma, D. V. Edmonds, Phase transformations in steels Volume 2: Diffusionless transformations, high strength steels, modelling and advanced analytical techniques, (2012)

7. ASTM A841, Standard Specification for Steel Plates for Pressure vessels, Produced by ThermoMechanical Control Process (TMCP), (2013)

8. ASTM A1066, Standard Specification for HighStrength Low-Alloy Structural Steel Plate Produced by Themo-Mechanical Controlled Process (TMCP), (2011)

9. A. Fandika, PHM Specification MHK-COMP-SPERPE-MAT 0101 - Specification for Carbon Steel Line Pipe, (to be published) 